\title{
DETERMINAÇÃO DE BENZO(A)PIRENO EM PESCADOS ${ }^{1}$
}

\author{
Antonio AZEREDO², Maria Cecília de Figueiredo TOLEDO ${ }^{2, *}$, Mônica Cristiane Rojo de CAMARGO²
}

\section{RESUMO}

No presente estudo, peixes, camarões, mexilhões e carnes de siri frescos e processados, comercializados na região metropolitana de Campinas (SP), foram analisados quanto à presença de benzo(a)pireno (B(a)P). A metodologia utilizada envolveu extração com n-hexano, limpeza em Sep-Pak sílica plus e determinação por Cromatografia Líquida de Alta Eficiência com Detector de Fluorescência. A presença de B(a)P foi detectada em todas as amostras analisadas ( $\mathrm{n}=35$ ), em quantidades variando na faixa de 0,03 a $4,54 \mu \mathrm{g} / \mathrm{kg}$. Os maiores níveis de contaminação foram encontrados em produtos defumados (níveis médios=2,5 $\mu \mathrm{g} / \mathrm{kg}$ ) e mexilhões (níveis médios $=2,4 \mu \mathrm{g} / \mathrm{kg}$ ). Considerando-se o potencial carcinogênico desse contaminante e a importância desse grupo de alimentos na dieta, um programa de monitoramento deve ser iniciado para identificar e controlar a fonte de contaminação de pescados por $\mathrm{B}(\mathrm{a}) \mathrm{P}$.

Palavras-chave: hidrocarboneto policíclico aromático, pescados, peixe defumado.

\section{SUMMARY}

DETERMINATION OF BENZO(A)PYRENE IN FISH PRODUCTS. In the present study samples of fresh and processed fish, shrimp, mussels and crab meat commercialized in the metropolitan area of Campinas (SP), Brazil were analysed for benzo(a)pyrene (B(a)P). The methodology involved extraction with n-hexane, clean-up on Sep-Pak silica plus and determination by High Performance Liquid Chromatography with a Fluorescence Detector. B(a)P was detected in all samples analysed ( $\mathrm{n}=35)$ at levels ranging from to 0.03 a $4.54 \mu \mathrm{g} / \mathrm{kg}$. The highest content of B(a)P was found in smoked products (mean level=2.5 $\mu \mathrm{g} / \mathrm{kg}$ ) and mussels (mean level=2.4 $\mu \mathrm{g} / \mathrm{kg}$ ). In view of the carcinogenic potential of this widely distributed contaminant and the importance of seafood in the daily diet of fisherman communities, a monitoring program should be initiated to identify and control the source of contamination of seafood by B(a)P.

Keywords: polycyclic aromatic hydrocarbons, seafood, smoked fish.

\section{1 - INTRODUÇÃO}

Hidrocarbonetos policíclicos aromáticos (HPAs) são contaminantes amplamente distribuídos no ambiente [10, 21 ], cuja importância se deve ao seu potencial carcinogênico em animais de laboratório [9] e por relacionarem-se com alguns tipos de câncer no homem [19]. Entre os HPAs carcinogênicos, destaca-se o benzo(a)pireno (B(a)P), que por ser o mais bem estudado do grupo e por sua potente ação carcinogênica $[12,5]$, tem sido utilizado como indicador da presença de HPAs em alimentos [8, 21].

A cada ano são derramados nos mares de todo o mundo cerca de 5 milhões de toneladas de petróleo, uma conhecida fonte de HPAs [6]. Estes compostos são persistentes, principalmente em ambientes aquáticos, devido a sua baixa solubilidade em água e pela tendência de se associarem com material particulado, uma importante fonte de alimento para um grande número de organismos marinhos [15].

\footnotetext{
${ }^{1}$ Recebido para publicação em 1/12/2004. Aceito para publicação em 23/1/2006 (001444)

${ }^{2}$ Departamento de Ciência de Alimentos, Faculdade de Engenharia de Alimentos. Universidade Estadual de Campinas (Unicamp)

Rua Monteiro Lobato, 80

Caixa Postal 6121

CEP 13083-862 - Campinas (SP)

E-mail: macecil@fea.unicamp.br

*A quem a correspondência deve ser enviada
}

Peixes não processados apresentam concentrações de HPAs bastante baixas, mesmo quando capturados em locais contaminados. Isto se deve à grande habilidade do sistema metabólico de peixes em biotransformar HPAs em dióis, epóxidos e outras substâncias [16]. Peixes defumados sob condições controladas têm, normalmente, quantidade inferior a $1 \mu \mathrm{g} / \mathrm{kg}$ de B(a)P (na faixa de 0,1 a $0,5 \mu \mathrm{g} / \mathrm{kg}$ ); porém, estes valores podem ser ultrapassados no caso de defumação excessiva. A incidência de câncer de estômago em grupos da população da Nigéria [1] e dos países bálticos [3] tem sido relacionada com o grande consumo de peixe defumado artesanalmente, contendo elevados níveis de HPAs. Os moluscos, por não possuírem mecanismos rápidos de biotransformação e acumularem HPAs e outros poluentes, são considerados organismos sentinela, e têm sido largamente utilizados para monitoramento ambiental.

Vários métodos para a determinação de HPAs em peixes, moluscos e crustáceos por Cromatografia Líquida de Alta Eficiência (CLAE) já foram descritos na literatura e muitos deles envolvem etapas de saponificação, extração da fração insaponificável por meio de partição líquido-líquido, purificação da amostra e determinação analítica [3, 18].

Até o presente momento desconhecem-se pesquisas dirigidas ao monitoramento da presença de $\mathrm{B}(\mathrm{a}) \mathrm{P}$ em pescados disponíveis no mercado brasileiro, embora já existam trabalhos que descrevam a ocorrência deste contaminante em outros alimentos como óleos e produtos cárneos [14, 